Critical Review

\title{
The Social Nature of Argumentative Practices: The Philosophy of Argument and Audience Reception
}

\author{
By Christopher W. Tindale
}

Cambridge: Cambridge University Press, 2015. Pp. xii, 1-244.

ISBN 978-1-107-10111-1 Hardcover CDN\$119.70, Paper

CDN\$33.95

\section{Reviewed by Paula Olmos}

Universidad Autónoma de Madrid

Facultad de Filosofia y Letras

Despacho 303-Módulo IVbis

Avda. Francisco Tomás y Valiente, 1

28049 Madrid

Spain

paula.olmos@uam.es

Abstract: This article reviews Christopher W. Tindale's The Philosophy of Argument and Audience Reception (Cambridge, 2015).
Résumé: Cet article est une critique de The Philosophy of Argument and Audience Reception (Cambridge, 2015) de Christopher W. Tindale.

Keywords: Aristotle, audience, audiences, argument, emotion, Perelman, philosophy of argument, reason, rhetoric, rhetorical argument, Tindale

Christopher W. Tindale's latest book approaches, in a particularly ambitious and meticulous way, the construction of a "philosophy of argument", i.e., a conceptual and theoretical framework for the analysis and elucidation of argumentative practices, which intends to do justice to the role played in it by the audience(s). In order to do that, he seeks the assistance of certain philosophers who, in their efforts to understand argumentative and deliberative process-

(C) Paula Olmos. Informal Logic, Vol. 38, No. 1 (2018), pp. 151-183. 
es, had already shown their inclination to take account of the audience as an active and regulative agent: namely Aristotle (Ch. 3) and Chaïm Perelman (Ch. 4) - as could easily be expectedand, somehow less obviously, Jürgen Habermas (Ch. 5).

Moreover, in his search for useful suggestions and convergent viewpoints, Tindale also reverts, in his really unprejudiced inquiry, to other kinds of reflections not directly focused on argumentation but exploring diverse aspects of its linguistic, cognitive and social infrastructures. He revises, thus, H.P. Grice's and R. Brandom's pragmatic models, with some supplementary references to D. Sperber and D. Wilson's relevance theory (Ch. 6); J. Lackey's and M. Kush's proposals in the epistemology of testimony (Ch. 7); new perspectives on the cognitive psychology of emotions proposed by A. Damásio, P. Thagard or R. de Sousa who, curiously enough, recover certain Aristotelian suggestions (Ch. 8) and, finally, the illuminating considerations on the interactive construction of agency and personal identity by M. Quante and A. Sen who, in their turn, exploit a recognizably Habermasian approach (Ch. 9).

When, in the final chapters of his book (Ch. 10-Ch.12), Tindale faces the task of using his crammed conceptual toolbox to respond to certain theoretical problems posed by argumentative practices, he will start by claiming that all these branches of scholarly research have recently taken a common and convergent social turn: "a shift of perspective to the concerns of the social" (p. 181). Accordingly:

(a) theories of meaning become externalist and are not anymore (or not just exclusively) based on the speaker's intentions;

(b) the renewed interest on testimony as a source of knowledge resituates it within an interactive and collective context of epistemic production (and not anymore just epistemic transmission), i.e. a context of "epistemic dependence";

(c) the cognitive role and the meaning of emotions become founded upon a socialized web of expectations, recognitions, sanctions and capabilities for influencing and mobilizing; 
(d) and, likewise, the processes of acquisition, development and stabilization of a personal identity are conceived of as supported by social interactions in which the individual deploys her agency, particularly in her capacity to give, ask for and interchange reasons.

This common "social turn" found in the different inquiries explored by the author, allows him to exploit all those theoretical frameworks in construing a model of argument that's similarly collective, interactive and socialized. Tindale's model emerges, thus, from his radical assumption of the active co-constructive character of the diverse agents taking part in an argumentative practice and his likewise radical rejection of the exclusive attribution to the arguer, as a single individual, of the rank of argumentation source and full controller:

Argumentation has a dynamic nature to it, with arguers and audiences wedded in an active relationship of exchanges to such a degree that the audience provides much of the content of the discourse because they are so central to the context. The discourse is for them, and so is composed in their terms. In this way the arguer is constrained in what he or she can say if persuasion is the goal. The arguer is not an isolated performer but an engaged coconstructor of the discourse (p. 4).

As could be inferred from the variety and relevance of its sources, I will not be able to comment on all the remarkable and thoughtprovoking ideas contained in Tindale's book. On the other hand, the exploratory character of most of the text and the somewhat programmatic tenor of its final chapters-leaving aside, for the moment, its detailed construction of an enriched concept of "cognitive environment"-make it difficult to identify a schematic theory or model as its conclusion. Taking in account, moreover, Tindale's particularly rich style, manifestly sensible to entangled philosophical problems, a direct reading of the text, which I earnestly recommend, cannot be replaced by any review or commentary. I will therefore just try to select, from every chapter, the points I have found most noteworthy, novel or challenging, also mentioning some possible critical aspects. 
The first two chapters are introductory to the book's themes and state the author's assumptions and starting points. The previous quotation from p. 4 is, I think, a telling sample. In order to illustrate the creative interconnection between the arguer and her audience, Tindale resorts here to three of Barack Obama's speeches, pertaining to three different moments of his road to the US Presidency. What is most evident in them is their common appeal to shared values, images and symbols and their mobilizing mode of address oriented to obtain a collective transforming action. The brief commentary that accompanies these speeches already reveals the enormous difficulties of Tindale's intended project. According to the author, we still don't have a proper theory of the audience; one that would conveniently account for the multiplicity of interactions that we in fact find when confronted with real cases of argumentative practice, i.e., that would identify, individualize and systematize them. With the idea of emphasizing this interactive complexity, Tindale mentions that F. van Eemeren "notes for example, that there may be primary and secondary audiences, where the latter is used to reach the former, which is the intended audience" (p. 19).

According to Tindale, when trying to respond to these theoretical and conceptual issues, we have, first to assume the basic or fundamental character of our role as audience:

It is clear, as was previously indicated, that we also express our argumentative nature by asserting ourselves, that we operate as arguers. But the suggestion here is that we can operate in this way only because we first operate as audiences, because we fully live the condition of being an audience. On such terms the audience is the more fundamental argumentative experience. It also suggests that our appreciation of being arguers and entering the practice of arguing starts from a prior appreciation of being in audience. (p. 21)

The priority of such being in audience (an expression Tindale takes from James Crosswhite) vis-à-vis the role of the arguer has as an immediate (although perhaps not so obvious) consequence which is the priority of the communicative space vis-à-vis the 
mental or reasoning space. ${ }^{1}$ That's why the quotation from $\mathrm{R}$. Brandom offered here by the author becomes so enlightening: "It is Brandom's contention that the monological is "parasitic on and intelligible only in terms of the conceptual contents conferred by dialogical reasoning" $(1994,497)$ (p. 22). ${ }^{2}$ Following this same idea, I would personally add that in "the game of giving and asking for reasons", 3 it is the asking for that is prior to the giving, or rather, giving reasons is something done in a context in which reasons are asked for and expected and in which there is a previous conception of what will be accepted (and assessed) as such-a conception that might well vary with the exchange itself.

Tindale will stick to this general idea throughout the book, emphasizing the import of a socialized practice of argument against the analysis of its alienated (distilled or transcribed) product. The intended task is to (at least) delineate some answers to certain questions posed by argumentation theorists regarding the role of the audience(s); namely:

(a) their problematic identification (a particularly vexed case would be what T. Govier calls "non-interactive audiences", a denomination that Tindale will reject);

(b) the correct definition and understanding of the process of persuasion, both as the connection that emerges between the arguer and her audience and as the aim of an "invitational rhetoric";

(c) and, finally, the clarification of the role played by (or attributed to) the audience in the assessment of arguments.

\footnotetext{
${ }^{1}$ In H. Mercier and D. Sperber's terms and in line with their "argumentative theory of reasoning", 2011, 2017

${ }^{2}$ In spite of the fact that Brandom's use of "reasoning", as revealed by the adjective "dialogical", implies a communicative and not a mental sense of the term, opposed to Mercier and Sperber usage.

${ }^{3}$ Of course Tindale also mentions this well-known formula from Brandom. Along the book though it is sometimes modified into "giving and receiving" or "giving and exchanging" reasons, while I claim that "giving and asking for" emphasizes the active role of interlocutors in a way that's more helpful to Tindale's own stance.

(C) Paula Olmos. Informal Logic, Vol. 38, No. 1 (2018), pp. 151-183.
} 
It is on this last topic that I think Tindale really makes his most important and innovative contribution, cogently countering the usual critique made to rhetorical approaches implying a misguided assimilation of the force of reasons to their persuasive effectiveness. Tindale shows that, without deserting a rhetorical framework, it is possible to construe and defend a more sophisticated view of argument assessment. However, I must say that the book tends to concentrate mostly on what I would call silent assessment, acting both prior to the arguer's communicative action (restricting and determining her choices) and after it, in the reactions of her audience (substantiated in effects of persuasion and mobilization). The author pays less attention to more dialogical or polylogical contexts or to communicative ways of argument evaluation. He does not explore publicly expressed and explicit modes of commitment, assent, distinctions, nuances, restatements, critiques, objections, counter-arguments or dissent. Argument assessment as an argumentative practice in itself doesn't really find its place in Tindale's account.

Only towards the end of the book, in his discussion with Trudy Govier, who only considers interactive an audience that effectively speaks out - and who, accordingly, labels as non-interactive and dispensable for argumentative analysis most of the audiences that interest Tindale, a stance which he will obviously oppose--, does the author mentions that: "They can and do 'talk back,' and we cannot function well without listening to those voices" (p. 215). However, this is not the kind of evaluative response on which he focuses his research in this book. I would suggest, though, that it could help and complement it greatly and would give better sense to some of his most interesting assumptions as the idea to attribute to the argument a dynamic (p. 4) or organic (p. 23, quoting Toulmin) nature. ${ }^{4}$ If, quoting Hamblin, Tindale explicitly rejects the socalled God's eye view (p. 32) as a relevant evaluative instance, he could have also followed him in attributing to the logician (the argument's evaluator par excellence) the role of a trained advocate

\footnotetext{
${ }^{4}$ Tindale has nevertheless developed a more dialectical approach to the idea of a "dynamic concept of argument" in a text written after the publication of this book (Tindale 2017, pp. 20-23).

(C) Paula Olmos. Informal Logic, Vol. 38, No. 1 (2018), pp. 151-183.
} 
(one that discusses and scrutinizes arguments) instead of a judge (one that passes judgment on arguments). ${ }^{5}$

Chapter 3, dedicated to Aristotle, begins Tindale's exploration of relevant sources for his intended audience-centered philosophy of argument. His deep knowledge of Aristotle's Rhetoric and the appreciation he shows for it enables Tindale to exploit its full potential, revising some of its well-known topics as well as some more hidden treasures. If, in Acts of Arguing (1999), the enthymeme was conceptually presented as an argument for whose completion and understanding an audience is needed, here we find the even more elucidating idea that the audience acts, even prior to the arguer's enunciation, as the social body that owns and preserves the (public) repository of common "places" that make the very enthymeme understandable as an argument:

The act of completing the argument oneself should contribute to the kind of self-persuasion characteristic of rhetorical argumentation; yet further aspects of persuasion may also be required. But for our purposes the point to be made lies in the availability of common "places" that both arguers and audiences can have recourse to in packing and unpacking argumentative discourse ( $\mathrm{p}$. 39).

Audiences and auditors have at their disposal enough "warrants" (in Toulmin's sense) that may serve to indicate to them what kind of reason-for-a conclusion they are confronted with (although, a first guess might be subsequently clarified, further restricted or corrected in the course of the exchange) and this is what makes possible their argument reception and assessment. Arguers, on their part, can count on such a repertoire-somehow pre-supplied by their audiences - when construing their speeches, i.e., during the phase of inventio or heuresis.

It is this capacity "common to all" to recognize reasons-given by our primitive condition of being in audience - that is the basis of both: (a) the more or less spontaneous practice of argumentation and (b) the technical exploration of its current resources. Jean

\footnotetext{
5 "The logician does not stand above and outside practical argumentation or, necessarily, pass judgement on it. He is not a judge or a court of appeal, and there is no such judge or court: he is, at best, a trained advocate", Hamblin 1970, p. 244.

(C) Paula Olmos. Informal Logic, Vol. 38, No. 1 (2018), pp. 151-183.
} 
Goodwin's felicitous phrase when commenting on Tindale's book during the last OSSA Conference $(2016)^{6}$ is so far, to my knowledge, the best summary of this idea: "The very idea of reason is that it is something that might be accepted by others".

In order to support the democratically extended and basic character of rhetorical (i.e., argumentative) identity and agency among all human beings, Tindale mentions both:

(a) the first paragraph of Aristotle's Rhetoric (I.1.1, 1354a4-6) that maintains the communal nature of argumentative practice: "Hence all men in a manner have a share of both [sc. dialectic and rhetoric]; for all, up to a certain point, endeavor to criticize [eksetazein] or uphold [hypexein] reasons [logon]",

(b) and the well-known Aristotelian characterization of rhetoric as a dunamis, a capacity or faculty (1355b20).

Even though it is a capacity or faculty that might be improved - this would bring about "becoming enthymematic" (enthymèmatikós, 1355a11-14), i.e. skilled in using enthymemesand which admits of a systematic investigation of its technical aspects, it is nonetheless grounded on a basic competence, emerging from our social participation in discursive exchanges:

James Crosswhite (2013) speaks of rhetorical capabilities, and while most of these appear as what we might identify as secondorder capabilities, they assume an underlying first-order capacity

\footnotetext{
${ }^{6}$ The last OSSA Conference (University of Windsor, 18-21 May 2016) dedicated one of its sessions to a "Book panel" on C. Tindale's The Philosophy of Argument and Audience Reception, with contributions by Jens E. Kjeldsen, Manfred Kraus, Jean Goodwin and Christian Santibáñez. However, only the commentaries of the two first mentioned have finally been published at the OSSA11 Proceedings site:

http://scholar.uwindsor.ca/ossaarchive/OSSA11/bookpanel/

${ }^{7}$ Even with the difficulties of the translation (the verbs eksetazein and hypexein are rather common, have multiple uses, and have received differing interpretations), it seems that Aristotle is using a pair of verbs to establish an opposition between acting as an auditor and acting as an arguer in relation to the logos exchanged. So this would be the Aristotelian version of "giving and (critically) receiving reasons".
}

(C) Paula Olmos. Informal Logic, Vol. 38, No. 1 (2018), pp. 151-183. 
to think or see rhetorically - to recognize rhetorical messages and judge them in line with our own interests and desires (p. 42).

This is, I think, the most significant contribution of Tindale's revision of Aristotle's Rhetoric. His subsequent examination of the general categories and terms for classifying enthymemes (necessary, refutable, based on signs, based on likelihoods) is somewhat more confusing, although the well-known inconsistencies between the different Aristotelian texts are surely to blame. Their discussion offers us, nonetheless, two other crucial ideas:

(a) the explicitly non-formal (i.e., substantive and ampliative) characterization of enthymemes and arguments in general, with which Tindale admits to be going beyond the Aristotelian texts and

(b) the extension of the commentaries made about the functioning of enthymemes also to paradigmatic arguments; a topic about which I have also written elsewhere (Olmos 2015, pp. 202-205).

Both ideas are clearly expressed in the following paragraph which merits being quoted at length:

Thus, the invalid arguments [sc. according to formal logic] remain by nature refutable yet can still be reputable if used in an appropriate way that is warranted by the audience. This is the account that remains absent from the text. It is wrong to conclude that all the wise are just on the evidence that Socrates was both wise and just. What follows is that some are just. But again, that would be to insist on what follows necessarily, not what is persuasive. Of course, the generalization in the conclusion does not have to be absolute and while we can only speculate again, a defeasible generalization would meet the requirements of many audiences. The "wise are just generally" is refutable but not defeated by a counter-instance. Attention shifts to the right kind of evidence that would make such a claim seem reasonable, and to a specific audience the case of Socrates would be the right kind of evidence. The power of a sign (like the example or paradigm) lies in the appropriate choice, and that will be governed by the demands of the audience. The right sign that has currency for an audience will help it grasp a point (a principle or general statement) towards which it may already be sympathetically disposed and thus bring about a

(C) Paula Olmos. Informal Logic, Vol. 38, No. 1 (2018), pp. 151-183. 
persuasive result $[\ldots]$ Thus, what will count as evidence (whether signs or likelihoods and paradigms, for which similar cases could be made) will depend upon the circumstances involved and, crucially, the audience at issue in those circumstances (pp. 49-50).

Even though, in my opinion, with this noteworthy interpretation of the Aristotelian rhetorical framework, Tindale has already established the (best) basis for understanding the normative role of audiences, it is in Chapter 4, centered on Perelman's contributions, when he explicitly assumes the responsibility of responding to the traditional complaints of logicians and dialecticians about the lack of normativity of the rhetorical approach.

Tindale's basic strategy here is trying to exploit Perelman's own philosophical device to answer those complaints and critiques. Therefore he proceeds to elucidate the controversial concept of the "universal audience" which is, in principle, thought to embody the kind of argument evaluator that would be stricter and more exigent than any other concrete or particular audience. However, along this chapter, Tindale will precisely emphasize that the universality of the universal audience should not be understood, in a Cartesian mood, as an atemporal, aspatial and objectivist instance. Tindale's recent work on Perelman's concept of "regressive philosophy" allows him moreover to avoid certain current interpretations for which the reasonableness of the "universal audience" would be associated with "self-evidence". This idea is completely alien to Perelman for whom philosophy «is a way of thinking and speaking [...] a subject that embraces all that falls outside of science and whose proper method is argumentation» ( $\mathrm{p}$. 63); "Regressive philosophy sees all knowledge as incomplete and subject to the revision of later experience, hence its stress on openness [...] This philosophy is, indeed, always "underway" (p. $65)$.

According to this framework, Perelman's "universal audience" is interpreted as a construction of the speaker/arguer but one that is explicitly related to the circumstances and conditions in which she really acts: "This construction, then, is not a free act of the imagination, but an activity constrained by the exigencies of a real situation with a real audience to be addressed" (p. 59). The "universal audience" that emerges from Perelman's own efforts to 
clarify the initial confusions provoked by this concept ever since the publication of The New Rhetoric (1958) ${ }^{8}$ : "is not absolute, it is not timeless, and it does not possess a self-evident character. It is relative to the particular audience, time and place, to the argumentative situation, for which it is relevant" (p. 68). Such "universal audience" would rather be characterized as the standard of reasonableness that's operative in a concrete context.

Tindale thinks as well that Perelman's rhetorical concept of "adherence", identified as the aim of argument, has something to offer. On the one hand, it's a conveniently comparative and not a qualitative concept. On the other, as an aim of argument, it goes well beyond merely intellectual assent before a thesis or conclusion:

Indeed, adherence begins as a state of the mind, as an intellectual contact, but as it develops it encompasses the entire person and is no longer just the intellectual connection of its origin. The aim is not purely intellectual adherence, but the inciting of an action or creating a disposition to act, since the uptake need not be immediate (p. 70).

With these ingredients, Tindale will undertake the reconstruction of the workings of argumentative normativity according to a Perelmanian framework. According to Tindale, even if it's true that Perelman and Olbrechts-Tyteca follow in their Treatise rhetorical tradition and speak about the effectiveness of discourse in relation to a particular audience, maintaining that for them argument strength is measured solely by means of such effectiveness would be to misunderstand their much more sophisticated proposal ( $p$. 71). Among other things, effectiveness, in their terms, taking in account what has already been said about "adherence", involves not only (intellectual) conviction but purports the kind of (integral) persuasion capable of mobilizing the auditors. And this implies that it shouldn't be evaluated until the persuaded individuals would actually undertake the intended actions. By contrast, the assessment of the arguments' strength is something that pertains to

\footnotetext{
${ }^{8}$ Tindale uses the compilation of essays The new rhetoric and the humanities: Essays on rhetoric and its applications (1979) and The realm of rhetoric (1982), that is, the English translation of L'Empire Rhétorique (1977).
}

(C) Paula Olmos. Informal Logic, Vol. 38, No. 1 (2018), pp. 151-183. 
the context of argumentative exchange and responds to a notion of validity that's operative in it; a notion of validity that, in any case, is not well captured by its formal counterpart.

Maybe this would have been a good moment to evoke and explore the kind of dynamic evaluative interchange that I referred to previously, but the author is not very explicit as to what he has in mind in practical terms. His mention of the "rule of justice" (i.e., equal treatment of equal cases) as the basis of the soughtafter Perelmanian concept of validity is, nevertheless, important and clarifying. The "rule of justice" would, on the one hand, operate as the basis of recognition of relations of analogy between arguments and, on the other, as presiding over the standards of reasonableness and validity that are already present in the discursive contexts prior to the presentation of the arguments. The role of commonplaces and scheme warrants is, in this case, mostly equivalent to the one emerging from the Aristotelian framework.

Audiences and auditors may, according to this setting, recognize and assess the arguments' validity-while experiencing their effectiveness-because they belong within a community that argues, that has actually been arguing long enough and that continuously revisits its standards of reasonableness. The argument offered in one particular occasion is, therefore, based on precedent (and it's interpreted and assessed as such) and aspires, in its turn, to become precedent itself:

When Perelman and Olbrechts-Tyteca suggest that strength must be appraised by the rule of justice, this is the idea that comes to the fore: That arguments are directed at audiences who have a history, who do not emerge anew at each step, but draw on their past judgments in making the next one. While the efficacy of the argument affects them now; the validity stands apart from this, and draws on their past and is projected into their future. [...] To judge Perelman's account as one interested only in the effectiveness of argumentation fails to appreciate the whole picture. [...] Arguments, then, are experienced within communities that have their different measures of strength, their ways of being reasonable. That disagreements arise over the reasonable is empirically evident. That is why the need for argumentation exists. What supports the above interpretations are the statements made on the reasonable: "what is reasonable must be able to be a precedent which

(C) Paula Olmos. Informal Logic, Vol. 38, No. 1 (2018), pp. 151-183. 
can inspire everyone in analogous circumstances, and from this comes the value of the generalization or the universalization which is characteristic of the reasonable" (Perelman 1979: 119). (p. 73).

According to this conception, the generalization of a, prima facie acceptable, shared standard of reasonableness would tend to yield a usable warrant — or a recognizable argument scheme-while the analogy between arguments (precedent and present) could always be alleged as an assessment procedure, beyond the explicit recognition of such general standards. All these considerations do not imply leaving behind a rhetorical approach in order to embrace logical evaluation. On the contrary, what's at stake is understanding how logical assessment (undertaken within a theoretical framework based on inter-argumentative relations) is incorporated both in the way the arguer builds her discourse, by taking in account the auditors she is in fact facing and their standards of reasonableness, and in the way the audience recognizes what's delivered by the arguer as intentionally conforming to those standards, and so, as a piece of argumentative speech, offering reasons for a certain conclusion.

The next chapter (Ch. 4) regards J. Habermas and begins with Tindale's acknowledgement of the increasing number of references to this philosopher in the most recent studies on argumentation. It is true that his influence in the first stages of our forming discipline has been well attested, but he didn't seem to have the presence in it that might have been expected from that fact. Now, instead, while many scholars in the field turn to the study of argument in the public sphere, Habermas becomes again a source of inspiration. One could be tempted to think that Habermas' wellknown model of deliberation and communicative action would be too ideal for Tindale to find in it the kind of relations between arguers, auditors and arguments that he's looking for. But it is always possible to make a regulative use of Habermas prescriptions in any real situation of communication and in counterfactual contrast with its manifest conditions:

The point is, rather, that participants in argumentation should think counterfactually, which involves contrasting their social situation with a universal on which it might be predicated. While we

(C) Paula Olmos. Informal Logic, Vol. 38, No. 1 (2018), pp. 151-183. 
cannot escape from our social contexts, the argumentative practices of justification allow us to think outside of them (Habermas 1996: 323) (p. 85).

Beyond these initial cautionary remarks, Tindale's exploration of the Habermasian framework focuses on the explication of the concept of Lebenswelt or "lifeworld", which is a kind of context or realm, allegedly shared by those who take part in communicative action, that's structured in three levels - this threefold structure being something that's also allegedly shared, at least in the most common situations of our cultural practices. The three levels or dimension of this lifeworld are: (a) the objective world of objects and states of affairs, which is the source of factual or theoretical claims; (b) the intersubjective space of norms and values, the source of practical and normative claims and (c) the individual's subjective sphere of private thoughts and emotions, the source of evaluative claims (p. 85). Those who prove capable of assuming and understanding this three-level structure of the lifeworld (that Habermas seems to consider basically universal and atemporal, although that would be a controversial stance) and learn how to competently move and act in it (correctly assigning the corresponding standards of reasonableness to each kind of claim), are the ones who also accomplish a "decentered" understanding of the world and of the debated issues that's the appropriate and desirable attitude according to this model.

Tindale uses all these Habermasian suggestions with some caution. He is conscious of the critiques they have received due to the excessive strictures of such a normative framework that, according to some scholars, tends to condemn as irrelevant alternative or unorthodox views. However, Tindale seems to think that Habermas's vindication of a variety of "validity claims" (beyond purely theoretical thesis) that demands from us a careful exploration of the operative workings of the "the force of the best argument" (beyond the models of deductivism and probabilism) establishes a theoretical framework that's too precious for argumentation studies to forgo. And he's right as long as it appears to be still necessary, even within the field of argumentation, to call for a proper attention to non-theoretical and non-propositional models of argument. The idea that we are all competent and feel at ease in

(C) Paula Olmos. Informal Logic, Vol. 38, No. 1 (2018), pp. 151-183. 
deliberations involving all three levels of our lifeworld is too attractive to be left outside of Tindale's audience-centered theoretical framework:

His rules for argumentation across the three levels assume inclusive audiences of competent speakers, and his discussion of validity claims assumes audiences uttering claims across the full range of human interests, from the descriptive to the normative, from evaluative to the explicative (p. 96)

Eventually-and this point will merit a more extensive development towards the end of the book-Tindale also praises the perspicuity shown by Habermas, precisely opposing R. Brandom, in discriminating among possible roles assumed by more or less involved participants in argumentative and deliberative exchanges. Habermas establishes, indeed, a distinction between listeners and hearers: while the former adopt a third person role attending the exchange, the latter face the speaker as directly addressed in their second person capacity that may demand from them an active response. Tindale thinks such distinctions could be more than useful in building a theory of audience sensible to diverse configurations and roles.

However, I see here a possible danger and a source of prospective problems. Habermas attributes the assessment duties to the listeners rather than the hearers and Tindales doesn't contradict him in that point. The reason seems to be that the listeners, if only for their bigger number and diversity, would embody a wider and more legitimate representation of the socially-standing standard of reasonableness, personifying a kind of Perelmanian "universal audience". Again, I think that the explicit critical response to arguments as a mode of evaluation is being somewhat disregarded: the silently assessing instance is deemed normatively stronger than the communicatively responding one. A good motive to do that is, obviously, to avoid the charge of favoring particularized effectiveness over socialized validity, but the danger of eluding precisely the domain in which such socialized validity is founded and disseminated, i.e. the dynamic practice of argumentative discussion, shouldn't be underestimated.

Chapter 6, among the most carefully and thoroughly construed and discussed in the whole book, explores ideas from the field of (C) Paula Olmos. Informal Logic, Vol. 38, No. 1 (2018), pp. 151-183. 
linguistic pragmatics that expectedly may yield useful tools for the author's agenda in building his "philosophy of argument". In this respect, Tindale's vindication of H.P. Grice's approach and strategies, even after revising the plausibility of part of the critiques he has received, is particularly enlightening. Tindale mentions Grice's careful and precise formulation of the maxims that inform the Cooperative Principle, especially emphasizing the way in which some of them (some additional sub-maxims in particular) seem to clearly contemplate the speaker's consciousness of the role of her interlocutor or audience:

In this respect, he [sc. Grice] suggests adding to his maxims of Manner one which governs such invitations [sc. invitations to reply]: "Frame whatever you say in the form most suitable for any reply that would be regarded as appropriate"; or "Facilitate in your form of expression the appropriate reply"' (1989: 273). This is an important addition on a number of fronts, but most particularly because it constitutes an explicit movement toward the audience (p. 103).

Tindale dedicates an enormous effort to dispute or at least mitigate the objections currently aimed against Grice's "intentional theory of meaning". Tindale's crucial strategy rests in attributing the increasingly complex and sophisticated formulations of the theory successively provided by Grice to his likewise increasing sensibility towards the place and role of the hearers/audiences in all their variety-including more or less absent, and even imagined or virtual audiences. According to Tindale, in spite of the difficulties posed by such diverse and problematic contexts, Grice will persist in including among the speaker's intentions those related to the hearer's recognition of such intentions. Tindale praises such persistence and illustrates its fruitfulness by citing a contribution of F. Kauffeld (2009) that would prove the relevance of this reflexive or second-level intentions of the speaker in accounting for the analysis of some real cases of argumentative exchange.

Moreover, Tindale seems to think that it is still possible to combine Grice's approach with the change of perspective brought by Sperber and Wilson in the 1980s. Their proposal of a "relevance theory" aimed, in fact, to reduce the maxims of conversation to the optimization of "an utterance's contextual relevance", with

(C) Paula Olmos. Informal Logic, Vol. 38, No. 1 (2018), pp. 151-183. 
regard to its meaning processing. If Grice's approach was centered on the position of a speaker who properly takes her hearer into account, the new perspective focused on the interpretation process conducted by that hearer situating the speaker's utterance in its context of relevance. Tindale's underlying idea in trying to combine them is that, taken in isolation, both approaches could prove partial.

Tindale will, in any case, pay even more attention to R. Brandom's pragmatics, attributing to this philosopher's theoretical framework a special capacity to account for and make sense of the public (i.e. externalized, intrinsically social) interchange of reasons. Brandom goes, indeed, beyond the mental contents and the intentional attitudes regarding such contents of those taking part in a linguistic exchange, to focus on publicly expressed commitments, on the speaker's accepted responsibility - accepted as an intrinsic rule of language use - of accounting and giving reasons for those contents and on the hearer's assumed practice, in her turn, to interpret them as justificatory or explanatory reasons for other conten

Part of being rational is to understand claims as potentially in need of reasons (1994: 214). Indeed, we have noted that such recognition is part of what is involved in our make-up as argumentative beings. [...] Giving reasons presupposes the possibility of asking for them, or of potentially standing in need of them. [...] Importantly, reasons, whether they justify commitments or bestow entitlements, are social (p. 119).

Tindale is particularly interested in the "social turn" brought by Brandom's "inferentialist theory of meaning" and in the intrinsic character of a normativity that's incarnated in communicative practice itself, according to which a correct (and consequently an incorrect) meaning interpretation isn't determined by reference to previously shared fixed meanings, but depends on the practice of the communicative act itself which is regulated by rules of cooperation: "Meaning is viewed from the perspective of individuals engaged in the shared practices of interpretation. [...] We inhabit a normative space" (p. 125).

The final balance of this revision of pragmatic theories mainly favors Brandom's approach. However, Tindale will insist on not 
forsaking some aspects of the Gricean framework that he still finds relevant and fruitful. If Brandom emphasizes the centrality of interpretation processes and Grice that of codification processes, Tindale claims that he aims at the recognizable space in-between: "A fruitful hypothesis to explore in a later chapter, then, is that meaning takes place between speaker and audience, arising from the network of commitments they share and the measuring of utterances against that network" (p. 126). That's his way of declaring that he will keep talking about "intentions" and their "recognition" as part of the conceptual framework for the analysis of argumentative practice.

Moreover, although Tindale doesn't really say it (he actually says almost the opposite), I consider that Brandom's refusal to speak about "shared linguistic conventions", even if it yields a notion of linguistic competence disconnected from characteristically unequal intellectual training (and this is indeed attractive for Tindale's approach, p. 125), implies renouncing a most useful (maybe irreplaceable) tool for the analysis of real cases of argumentative communication. Although Brandom's contention that neither "intentions" nor "conventions" explain, but rather both presuppose, linguistic practice might be philosophically illuminating (Brandom 1994: 232-233), identifying intentions and conventions at work in argumentative discourse might be practically an irreplaceable way of analyzing its recognizable characteristics in a shared context of highly institutionalized and culture-mediated practices.

In any case, Tindale chooses to keep exploiting Brandom's pragmatic model in the search undertaken in Chapter 7 for possible inputs for his philosophy of argument from within the epistemology of testimony. According to such model: "a speaker does not just take on the responsibility to justify her claim with reasons if challenged, she also lends her authority to the asserted content, licensing others to undertake a corresponding commitment" (p. 128). Testimony, as an epistemic source is, thus, directly related to the basis of arguments from authority and to reflections regarding the personal characteristics of the speaker/arguer (the realm of the ad hominem) above and beyond the contents of her own utterances.

(C) Paula Olmos. Informal Logic, Vol. 38, No. 1 (2018), pp. 151-183. 
Traditional epistemology has remained suspicious of the justificatory status of knowledge obtained from testimony, as revealing a kind of epistemic interdependence opposed to the ideal of the individual autonomy of cognitive agents, and has thus tried to consider testimony as a means just to transmit knowledge, as opposed to being a genuine source of it. But Tindale examines, in this respect, some recent contributions by J. Lackey (2008) or M. Kusch (2002) who have vindicated the centrality of testimony in any appropriately social approach to epistemology. A plausible characterization of testimony involves, thus, not only the communicative transmission of a witnessed content but in addition the consideration of the authority of the testifier as supporting it, so that the receptor or auditor is not only expected to adhere to the content but also (even primarily) to believe the speaker.

However, in order to appreciate the significance of this claim it seems that what is needed - according to Tindale and in line with Lackey's proposals - is an approach that would focus on audiences and communicative processes and be less obsessed with identifying the conditions (cognitive and mental) that testifiers should allegedly satisfy to offer a justified testimony. Tindale claims that with her Statement View of Testimony (SVT) Lackey: "shifts attention away from what speakers know or believe and onto what they say" (p. 137), and this seems crucial for taking advantage of these reflections on testimony in construing a philosophy of argument. My own contribution to this topic, from the same year as Lackey's work cited by Tindale (Olmos 2008: p. 67), proposed a very similar framework and rhetorical turn. It's not surprising that I absolutely share Tindale's positive view. ${ }^{9}$

Tindale also takes into account the contribution of M. Kusch, the proponent of communitarian epistemology (Kusch 2002), according to which once knowledge communities emerge, they acquire epistemic priority over their individual members, so that the knowledge claims of any individual derive their entitlement

\footnotetext{
9 Tindale (p. 143) quotes my contribution to the 2007 OSSA Conference, published later that same year in Informal logic 27/2 (although in the book it mistakenly appears as Olmos 2006), but I also published a second article on the same topic in the journal Theoria 23/1 (2008), whose conclusion emphasizes the focus on communicative processes in a way very similar to Lackey's.
}

(C) Paula Olmos. Informal Logic, Vol. 38, No. 1 (2018), pp. 151-183. 
from their membership in the community. It is true that the author recounts the effective tension (and real debate) between Kusch's communitarian approach that demands a plural, we-mode kind of intersubjectivity, and Brandom's insistence that what actual linguistic practices really establish, through effective local interactions between particular individuals, is an I-thou model of intersubjectivity. But Tindale, in a pragmatist mood, declares that: "Both construals of intersubjectivity are consistent with the results we see and the question of primacy practically (rather than theoretically) depends upon the context and the stages involved in the processes of developing knowledge" (p.143). He thinks, in any case, that what can really help us understand the basis of epistemic interdependence and common knowledge is the reexamination and wider development of the concept of "cognitive environment", as proposed by Sperber and Wilson (1986). It is the "manifest" character of such environments what makes them, according to Sperber and Wilson, accessible to speakers and their interlocutors (i.e. to arguers and audiences). Moreover, when we communicate and, thus, modify the relevant cognitive environment, what we do is make new contents accessible: "This is where what people say becomes a source for knowledge. And part of the reason we feel justified in trusting the testimony of some people (and not of others) is because it is manifest to us that we share a cognitive environment with them" (p. 146).

Cognitive environments will reappear and take a leading role in the last chapters of the book, but Tindale already states here that he shall not want to restrict the concept of cognitive environment as including just what's immediately and manifestly accessible in a given context. He defends, instead, that Brandom's inferentialist pragmatics recognizes and exploits connections between linguistic contents that may incorporate into our cognitive environment «a fund of collateral beliefs in light of which we interpret and understand those facts and assumptions once they become noticed» (p. 146).

The next chapter (Ch. 8), centered on the relationship between emotions and reason is rather organically connected to the previous one, focused on testimony. If the practice of testimony is related to the notion of trust in a speaker and if such trust is, for its

(C) Paula Olmos. Informal Logic, Vol. 38, No. 1 (2018), pp. 151-183. 
part, related to the perception of the speaker's character, then the assessment of trust will be a matter of both cognitive and emotional assessment (provided that these can be actually differentiated, which is what is really at stake): "As Paul Thagard (2006: 227) points out, the decision to trust others and what they say involves adopting emotional attitudes towards them" (p. 148).

Examining, precisely, the change of perspective proposed by many contemporary cognitive psychologists (especially A. Damásio and P. Thagard) who reject the traditional idea of a separation between emotions, on one side, and rationality and cognition, on the other-according to what could be considered a Platonic or Cartesian model of rationality - , Tindale takes the opportunity to vindicate the Aristotelian precedents of the new approach. Thus, he attributes to Aristotle: "the first clearly cognitive account of the emotions" (p. 150) and, in doing so, he also finds arguments to defend Perelman from the charge of neglecting pathos in favor of logos and ethos notably raised by Alan Gross. According to Tindale, Perelman's vindication of the "epideictic genre" is incompatible with such an accusation. Epideictic discourse is crucial for the generation and transmission of values, and these are directly related to emotions as Tindale approaches them, that is, emotions as both supported by and contributing to argumentative processes. In any case, the first part of Book II of Aristotle's Rhetoric is dedicated to emotions and Tindale finds two relevant points in the Aristotelian analysis that merit some comment:

In the first case, emotions in some way cause a change in judgment. They are directly related to how we view things, what attitude we take towards them and the way we arrive at decisions about them. Secondly, they are accompanied by pain and pleasure. These may be physical or mental, and perhaps both. But it indicates already a holism that will characterize Aristotle's discussions. The whole organism is addressed when speech aims at persuasion (p. 151).

The author does also emphasize the original and contemporary character of Aristotle's strategy in his discussion of each particular emotion. Although Aristotle does not follow a totally rigid scheme, in each case he tries to determine (a) the state of mind 
involved with each kind of emotion, (b) who the people (or kinds of objects) are towards whom the emotion will be felt and (c) the grounds on which the emotion is felt. The idea, to sum up is "to understand the nature of an emotion and the conditions that provoke it, presumably so that a speaker may learn to create such conditions and the associated emotions" (p. 152).

The clear similarities between the Aristotelian discussion and some contemporary approaches, especially, as Tindale emphasizes, in what regards Aristotle's assumed holism ("the whole organism is addressed when speech aims at persuasion", p. 151) and psychophysicalism ("all the pathe of the soul involve the body", $p$. 155), has not been as widely acknowledged as could have been expected. In any case, the idea that emotions are irrational human traits is nowadays clearly in retreat and this is fully in line with Aristotle's endeavor to capture the grounds that support them, according to the above-mentioned aspect (c) of each individual emotion.

Thus it is nowadays widely assumed that decision-making processes are not at all disconnected from emotional states but, on the contrary, seem to require emotions to work properly. Both Damàsio and Thagard have worked on this idea and tried to build new theoretical approaches for "emotional cognition". Thagard, in particular, defends a notion of "emotional coherence" that becomes essential for Tindale's argumentative framework:

If emotions play a crucial role in how we engage and understand the world, as the above suggests, then they are important as a means to persuasion [...] An important insight of Aristotle's Rhetoric flows from his treatment of the emotions. Because in showing that emotional responses are reasonable and involve cognitive processes he also showed that they were open to reasoned persuasion (p. 160).

Tindale makes, thus, use of the contributions of several cognitivist psychologists and philosophers with the aim of establishing a new perspective on emotions that would make their relation with argumentative processes explicit. But he intends to emphasize as well another kind of connection between emotions and their social sanction that's clearly present in the Aristotelian approach and nearly absent in contemporary discussions (with the possible 
exception, perhaps, of Damàsio's socially-acquired and culturallyrelated higher cognitive emotions, p. 157): "the accounts Aristotle gives of individual emotions indicate their social nature - they arise in relation to a person's perceptions of what is expected of them or due to them in specific circumstances" (p. 152). This is an important claim for Tindale's approach, as the audience becomes, according to it, not just the subject in which to provoke emotions but also the culturally-informed evaluator of their rationality.

Another crucial topic that's nevertheless just suggested in this chapter is the link between the emotions that are in play in a particular argumentative context and the effective activation of the actions that the arguer seeks from her audience. Leaving aside some comments on Perelman's emphasis on the epideictic genre (the kind of value-based and value-related discursive genre that cannot be understood apart from emotions, pp. 149-150), such link only appears to be explicitly mentioned in Ronald de Sousa's contributions: "De Sousa (1987) follows this line of thinking in arguing that emotions supply what is needed to turn argument into action" (p. 160). It's a connection that could have merited further comments. In any case, the relation between emotion and reasons, established in this chapter, and the exploration, in the next (Ch. 9), of the connections between the exchange of reasons and a notion of personal identity based on agency and interaction should provide us the right kind of orientation.

Taking part in argumentative exchanges, either in the role of the arguer or as a member of the audience implies, according to Tindale, exerting one's own personal agency in a sociallyconformed environment. Tindale decides, accordingly, to discuss theories of personhood, identity and agency. And he starts contrasting a classical notion of personal identity, like the one advanced by Locke, based on the requirement of certain constitutive features (generally associated with mental life and its continuity) to qualify as a "person", with contemporary approaches, as Michael Quante's, that tend to be of a more social nature:

By contrast to this, or in addition to it, we find definitions of persons as social beings constructed through their social interactions. For example, Michael Quante (2007) argues that persons are constituted by social relations. This means that integral to being a per-

(C) Paula Olmos. Informal Logic, Vol. 38, No. 1 (2018), pp. 151-183. 
son is being so treated or recognized by other [...] In this second, external, sense personhood is a status conferred on me by others. Interpersonal recognition flows both ways. Part of my understanding of myself as a person comes from my experience of being in the presence of other persons, being recognized by them and recognizing them (pp. 170-171).

However, keeping up with the whole book's eclectic and pragmatist trend-a kind of standpoint that makes the author favor the analytic fruitfulness of useful concepts against their ever polemic theoretical/philosophical foundation-Tindale claims that both internal and external notions of personhood are valuable for argumentation theory. Persons need to have certain rational capacities in order to take part in the practice of giving and receiving reasons but they also need to "be in relations with others, engaged in a social world that provides the content and occasion for argumentative exchange" (p. 172). Not every philosopher will be contented with this pragmatist-driven eclecticism. My own deeply sympathetic attitude could be further reinforced if Tindale's choice, in this and other similar cases along the book, was proved more evidently useful in the analysis of some real examples of argumentative practice.

Be that as it may, the most thought-provoking part of the chapter is probably the one that discusses Habermas's contributions and that allows Tindale to strengthen even more the link between personal identity and argumentative processes. On the one hand, according to Habermas, argumentative practices are among the interactions that contribute configuring a social environment for the stabilization of the individual (p. 175). On the other, moreover, argumentative practices facilitate making grounded decisions over other practices, that is over actions that people are expected to take, and involve deliberations regarding (and conducted in terms of) the characteristics of personhood, according both to an internalist notion of personal identity (the traits that determine our nature as agents who act for reasons) as well to an externalist one (our integration in and coordination with the groups to which we feel we belong). Tindale will finally support a characteristically Searlean stance, claiming that acting for reasons is ultimately part of what makes us (both internally and externally) persons:

(C) Paula Olmos. Informal Logic, Vol. 38, No. 1 (2018), pp. 151-183. 
An important, perhaps fundamental, aspect of the status-sense of personhood is the recognition by others that I act for reasons and, when called upon, can provide further reasons in justification of my actions. Likewise, in holding others responsible for what they do, I take them to be acting for reasons, reasons for which they could present further justifying reasons. That is, it is part of our recognition of personhood-in ourselves and in others - that the reasons in question do not just involve explanations for what motivates us but also those that issue from deliberation and choice. [...] Habermas gives voice to the same insight when he notes: "If we describe an event as being a person's action, we know for instance that we describe something which can be not only explained like a natural process, but also, if need be, justified" (Habermas 2003b: 107) (p. 178).

With these significant considerations, Tindale closes his panoramic review of philosophical and other related contributions that help him construe a philosophy of argument centered on audiences. The last chapters tend to be more personal and purposeful. Their aim is to show the possibilities of the theoretical framework construed and the performance of the conceptual tools found along the book in responding to certain definite questions posed by argumentation theory.

Chapter 10 revisits a topic with a long rhetorical tradition, "presence": a desirable quality that the speaker is expected to bestow on certain selected contents by a discourse skillfully built for such a purpose. Aristotle already mentioned ways to bring something "before-the-eyes" (prò ommátōn poieîn) (Ret. 1410b34$36 ; 1411 \mathrm{~b} 22 \mathrm{ss}$ ) among them different techniques that enliven the objects of discourse, infusing them with enérgeia (movement, action, vividness) and that would crystalize in the traditional rhetorical figure called hypotyposis ("Vivid description of a scene, event, or situation bringing it, as it were, before the eyes of the hearer or reader" OED). Perelman made also use of the concept of "presence" referring to the kind of effect, obtained by a mode of speech that emphasizes, illuminates or enhances a particular object to which we want to direct the attention of the audience, and that plays a significant role in argumentation. Taking in account the subtitle chosen by Tindale for his chapter on Perelman (Ch. 4), "a meeting of minds", it is quite understandable that he insist now on

(C) Paula Olmos. Informal Logic, Vol. 38, No. 1 (2018), pp. 151-183. 
the mental character of such "presence" as in Perelman and Olbrechts-Tyteca's use of the concept: "Traditionally, 'presence' has been understood as essentially making certain elements present to the mind, and using various techniques to accomplish this. A contemporary expression of this concern is provided by Perelman and Olbrechts-Tyteca" (p. 183).

However, Tindale will not approach the notion of presence in terms of prescriptive rhetoric. He will not focus on the possible stylistic choices of the speaker or arguer or on the exertion of her oratorical skill to obtain such effects (even though he refers to the efficiency in this sense of some of the examples taken from Obama's speeches and presented in Ch. 1). What seems to be most interesting for him is the (rather peculiar) way in which arguingany instance of arguing, be it more or less skillful - always makes certain objects or contents of speech "present" in the context of the exchange: "Arguments are vehicles that make something present" (p. 191). And here is where Brandom's pragmatics comes into play. It is not a question of transmitting what's already present in one mind (the arguer's) to other minds (those belonging to the members of the audience) by making it present there. Linguistic communication doesn't work that way: linguistic contents are not "directly shared" by minds. It is the action of the speaker, her saying something, that modifies the environment that's shared by both speaker and hearer, in a way that will be subsequently perceived by the latter in her own terms. Arguments, which are concrete, explicit and public interventions, "modify such environments by adding to, subtracting from or reframing what is already available" (p. 191).

It is precisely this requirement of an action that takes place in the public arena (an utterance) that, on one side, makes communication possible and, on the other, excludes the traditional metaphor of direct transference used to explicate it. Following this reflection, Tindale has no choice but to face one of the questions that's now haunting argumentation theorists, namely the way reasoning, arguing and inferring relate to each other: ${ }^{10}$ "in the game of giving

\footnotetext{
${ }^{10}$ Precisely the topic around which the last ECA Conference was organized (2nd European Conference on Argumentation, June 2017, Fribourg, Switzerland).

(C) Paula Olmos. Informal Logic, Vol. 38, No. 1 (2018), pp. 151-183.
} 
and receiving reasons, is the content of the reasons received identical to the content of the reasons given?" (p. 192). Certain ways of responding to this question open the possibility that such reasons may differ (at least in some sense) without this implying any failure either in communication itself, or in the fulfillment of the speaker's or arguer's intentions:

Reasons, we recall, are understood in relation to commitments, and those commitments stand in relation to others. The negotiation that goes on involves determining meaning against a background of collateral commitments that will differ from one person to another (p. 192).

The notions of presence, commitment and environment (or context) of an argumentative exchange (understood as "cognitive context") will stay with us until the end of Tindale's book. Chapters 11 and 12 focus on what the author calls "the experience of reception". In an audience-centered philosophy of argument, the process of reception cannot be understood as simply the passive endpoint of a chain of actions and events constituting the act of arguing, but on the contrary must be resituated as the generative instance that makes sense of the act itself. In this sense, Tindale recurs again to his particular interpretation of Grice's theory of meaning as more enlightening of the process of reception than is usually acknowledged. Tindale associates, thus, Grice's theory with certain claims made by M. Bakhtin on "enunciation": «For both philosophers [Grice and Bakhtin], what is said is said not just with an audience in mind, but in anticipation of a response from that audience» (p. 200).

It is nevertheless Brandom's pragmatic framework and especially his change of emphasis from (internal) intentions to (external and public) commitments what will allow Tindale to speak about a "cognitive environment". Tindale's cognitive environment will be structured by such commitments and by the expectations created by the interlocutors themselves with their communicative actions, which, in their turn, make it possible for them to construe and decipher the meaning of utterances. Moreover, the emphasis on commitments is also related to the inseparable link between contents and communicative agents: "Structuring the cognitive 
environment around commitments rather than beliefs further personalizes matters" (p. 205).

This "personalization" provides us with a model of analysis and understanding of discursive exchanges in general (and argumentative exchanges in particular) that's deeply situated and contextual; in which meaning arises from interaction itself between individual agents (agents endowed with their own history, their accumulated load of commitments and expectations, both held and created) taking place within a changing cognitive environment-and changing precisely because of discursive interaction itself. Tindale exploits this framework in order to comment on the specific features of a number of rhetorical resources. He mentions, in particular, the classical figures of metaphor, irony and allusion as modes of speech that reveal, probably more than plain speech, an expectation of interactive complicity between the speaker and her audience (pp. 206-208). These figures would be paradigmatic testimonies of the invitational nature of rhetorical communication.

Tindale also mentions - and I personally think that this is even more important for his purposes, as it is less dependent on the interlocutors' individual competence, educational level or just "personal style" - that some discursive interventions, instead of directly providing reasons, may be considered pre-argumentative (and the expression indicates both non-immediately argumentative as well as related to the argumentative function of language). Being pre-argumentative, such interventions tend to modify the cognitive environment in a way that prepares it for the subsequent reception of genuine reasons and arguments. In Tindale's own words:

This suggests two stages for the arguer to consider: There is the accepted stage of encouraging an outcome of thought or action by influencing the reflection and reasoning necessary. At this stage, a claim is advanced along with the reasons for it. But there is also suggested the prior stage of encouraging the conditions required for this to be properly received, of emphasizing choice in the context of a person's commitments (p. 206).

This idea could be fruitfully exploited in the rhetorical consideration of modes of speech which, not being explicitly argumentative (e.g. descriptive, narrative, informative), may nevertheless provide

(C) Paula Olmos. Informal Logic, Vol. 38, No. 1 (2018), pp. 151-183. 
categorizations and interpretations of particular elements of the cognitive environment aiming at their appropriate contribution to the argument's encoding and reception. It also reminds me of the empirical results presented by linguist H. Feilke in a paper (1996) whose consequences I have always found underexploited by argumentation theorists.

Even though Feilke started his empirical research with the, widely accepted hypothesis that the mature development of argumentative skills implied an increase in syntactical complexity and a more extensive and better use of connectives and discursive markers associated with the kind of speech that's structured in reasons and claims, his empirical results were surprising and therefore significant. The argumentative speech of his more advanced subjects (university graduates) showed a diminution in markers and connectives and an increase in contextual, informative material. Feilke interpreted those results in a way that closely conforms to Tindale's suggestions. According to Feilke, argumentation in mature subjects tends to be more enthymematic, less explicit and require from the receptor a more active role (Feilke, 1996).

Such pre-argumentative pieces of discourse, together with the proper resources of an invitational rhetoric, obtain (or at least emphasize) the desired presence of selected elements from the cognitive environment and this effect may, according to Tindale, work better and more effectively with some members of the audience than with others. And this means that their use in itself selects among the auditors a certain number who properly become addressees:

[a]ddressees stand out from audiences as those members who experience the reception of argumentation in a way more conducive to moving from the stage of conviction to that of persuasion, with the corresponding actions that such a move suggests. [...] The notion of "addressee" personalizes the audience. Or, rather, it activates aspects of the audience, moving them from potential to actual receptors of what is conveyed (p. 210).

In this sense, the "force of the arguments" understood, in Tindale terms, as the force experienced by their receptors, cannot be limited to the logical features of those arguments, to their strict conformation to the standards of reasonableness that are operative in a 
given context for a given audience. That force must also appeal to and satisfy individual and personal interests.

With these considerations, Tindale approaches the matters that occupy his book's last chapter, a chapter that explores the possibilities of the proposed theoretical framework to deal with the normative requirements of a theory of argumentation, the demand to take care of evaluative questions regarding the kind of discourse in which reasons are presented as support for explicit claims. Tindale faces this task assuming from the beginning the difficulties that rhetorical perspectives have always endured in dealing with normative matters: "Generally, we aspire to standards that are measurable and avoid relativism. Such standards have always been difficult for rhetorical argumentation, which is by its nature casebased" (p. 212).

Tindale understands, nevertheless, that the idea of the standards of reasonableness incarnated in audiences is worth pursuing. He revisits again Perelman's concept of a "universal audience" as a projection of certain standards of reasonableness made by the arguer herself but that, he insists, cannot be conceived of as disconnected from the real exchange with the real audience that the arguer is in fact facing. The speaker will have to explore and negotiate the reasonableness of her own proposals with her real audience, even if she tries to act, as it were, in advance, working out her results by devising a projection that really emerges from her previous contact with other audiences and from her own experience of being in audience. In my opinion, and to my delight, Tindale is here wonderfully categorical: "There is no alternative source for our standard of what is reasonable other than the activities of reasoners themselves" (p. 217). His grounds, if needed:

We recognize and reject the illegitimate bias, the irrationality, and illogicality, thus showing that a standard has been appealed to against which these flaws appear [...] It is fair to have recourse to this standard of reason because it is one that the particular audiences share in; it is drawn from the communities in which they operate. The wider our experience of audiences, moving among different communities, the more accurate our picture of what serves as current conceptions of the reasonable (p. 217). 
The reasonable will have, in any case, different dimensions (as real audiences and auditors have diverse dimensions). Following now Thagard and his integrative model of cognition that incorporates epistemic, social and personal features, Tindale suggests that the standards of reasonability will likewise appeal to epistemic values (truth, coherence, absence of bias), social values (wellbeing, competence, autonomy) and personal values (fame, wealth, power).

Thus Tindale finishes his book taking care of the intricate problem of the sources of criteria for argumentative assessment. And it is to be noted that beyond his categorical endorsement of the basic idea that such source is located in discursive practice itself, Tindale considers that it is ultimately possible to, as it were, "depersonalize" or "objectify" (at least partially) the repository of those criteria (and thus their effective operation, transcending their genealogy) by construing an adequate notion of "cognitive environment". A cognitive environment that would be conveniently enriched in relation to its ancestor in Sperber and Wilson's relevance theory, so that it may even merit a new denomination (not provided, though):

We can also now clarify the concept of cognitive environments in important ways: (i) They are not simply cognitive, but cognitive in the sense developed in this chapter and earlier in the study. They are both cognitive and emotional; they involve both facts and values. In this sense, "cognitive" environment may be a misnomer. (ii) They are modifiable spaces. In fact, they are continuously being modified as long as we live in society [...] (iii) It is a space that conditions the reception of argumentation. That is, it provides many of the preconditions of successful argumentation, and its nature will in turn contribute to the eventual success of argumentation. As we have seen, it is the place where rhetorical effects have impact (p. 222).

This final turn towards a concept that remains somewhat evanescent and disembodied and of which Tindale explicitly says that it plays a role similar to notions like "lifeworld" or "space of reasons" whose important feature is that "of being spaces where reasons are found" (p. 222), maybe blurs a little bit the basic and, to my view, more decisive point that there is no space for rational

(C) Paula Olmos. Informal Logic, Vol. 38, No. 1 (2018), pp. 151-183. 
grounding beyond argumentative practice itself. In any case, the dynamic play between the operative and effective discussion of our claims and our appeals to currently recognized standards of reasonableness may need the articulation of a theoretical concept representing somehow the relative stability (that can still be subjected to further challenges) of our evaluative criteria. That virtue is attributed by Tindale to his "cognitive environments".

Of course this remark or other observations offered along this critical note are just intended to do justice to the enormous interest inspired by Christopher Tindale's book. This is really a courageous piece of philosophical writing that takes on the immense task of construing all the way from its pragmatic, cognitive and social foundations a philosophy of argument that would take into account some of the most suggestive and advanced ideas and intuitions issuing from the field of argumentation theory in an effort to comply with one of its most cherished desiderata: the theoretical integration of its different traditional perspectives. In this sense, and even though its author acknowledges his rhetorical background and inspiration, I would say that The Philosophy of Argument and Audience Reception really manages to transcend that framework, advancing an integrative and widely significant understanding of argumentative practices. ${ }^{1112}$

\footnotetext{
${ }^{11}$ This review is an English translation by the author of: Olmos, P. (2016). "Reseña. Christopher W. Tindale, The Philosophy of Argument and Audience Reception", Revistalberoamericana de Argumentación 13: 1-28.

https://revistas.uam.es/index.php/ria/article/view/8050

${ }^{12}$ This work has been made possible by funds provided by the Spanish Ministry of Economy and Competitiveness through the Research Project FFI201453164-P, "The construction of argumentative agents in the practices of public discourse.
}

(C) Paula Olmos. Informal Logic, Vol. 38, No. 1 (2018), pp. 151-183. 


\section{References}

Feilke, H. (1996). "From Syntactical to Texual Strategies of Argumentation. Syntactical Development in Written Argumentative Texts by Students Aged 10 to 22", Argumentation 10(2): 197-212.

Hamblin, C.L. (1970). Fallacies. London, Methuen and Co.

Mercier, H. \& D. Sperber (2011). "Why Do Humans Reason? Arguments for an Argumentative Theory", Behavioral and Brain Sciences 34(2): 57-74.

Mercier, H. \& D. Sperber (2017). The Enigma of Reason. Cambridge MA: Harvard University Press.

Olmos, P. (2007). "Making it public: Testimony and socially sanctioned common grounds". Informal Logic 27(2): 211 - 227.

Olmos, P. (2008). "Situated practices of testimony. A rhetorical approach". Theoria 23(1): 57 - 68.

Olmos, P. (2015). "De entimemas, epiqueremas y esquemas". En. H. Marraud y P. Olmos (eds.) De la demostración a la argumentación. Ensayos en honor de Luis Vega (pp. 197-215). Madrid: Publicaciones UAM.

Tindale, C.W. (1999). Acts of Arguing: A Rhetorical Model of Argument. Albany, NY SUNY Press

Tindale, C.W. (2017). "Narratives and the Concept of Argument". In P. Olmos, ed., Narration as Argument, pp. 11-30. Amsterdam, Springer.

(C) Paula Olmos. Informal Logic, Vol. 38, No. 1 (2018), pp. 151-183. 